\title{
Microvascular function is preserved in newly diagnosed rheumatoid arthritis and low systemic inflammatory activity
}

\author{
Izhar C. van Eijk • Erik H. Serné • \\ Ben A. C. Dijkmans • Yvo Smulders • \\ Michael Nurmohamed
}

Received: 27 December 2010 /Revised: 13 March 2011 / Accepted: 4 April 2011 / Published online: 13 April 2011

(C) The Author(s) 2011. This article is published with open access at Springerlink.com

\begin{abstract}
Rheumatoid arthritis (RA) is associated with increased cardiovascular morbidity and mortality. Microvascular function has been linked to several risk factors for cardiovascular disease and may be affected in RA. It is, however, presently unknown at what point in the disease course the abnormalities in microvascular function occur. We determined whether microvascular function is already disturbed in early disease-modifying antirheumatic drugs (DMARD)-naive RA patients with low systemic inflammation. Fifteen consecutive RA patients with a median symptom duration of 5 months, a C-reactive protein level of $\leq 20 \mathrm{mg} / \mathrm{l}$ and without a history of cardiovascular disease, and age 15 and sex-matched healthy controls were recruited. Endothelium-dependent and endotheliumindependent vasodilatation in skin was evaluated with laser Doppler fluxmetry after iontophoresis of acetylcholine and sodium nitroprusside, respectively. Videomicroscopy was
\end{abstract}

\footnotetext{
I. C. van Eijk · B. A. C. Dijkmans · M. Nurmohamed

Department of Rheumatology, Jan van Breemen Research

Institute,

Amsterdam, The Netherlands
}

B. A. C. Dijkmans $\cdot$ M. Nurmohamed

Department of Rheumatology, VU University Medical Center,

Amsterdam, The Netherlands

E. H. Serné • Y. Smulders • M. Nurmohamed

Department of Internal Medicine and ICaR-VU,

VU University Medical Center,

Amsterdam, The Netherlands

M. Nurmohamed $(\bowtie)$

VU University Medical Center,

De Boelelaan 1117,

$1081 \mathrm{HV}$, Amsterdam, The Netherlands

e-mail: mt.nurmohamed@vumc.nl used to measure recruitment of skin capillaries after arterial occlusion. CRP and ESR levels were mildly, but significantly elevated in patients compared to controls. No differences in both endothelium-dependent vasodilatation and capillary recruitment were observed between groups $[709 \%(95 \%$ CI, $457-961 \%)$ vs $797 \%$ (95\% CI, $556-$ $1,037 \%), P=0.59$ and $37 \%$ (95\% CI, $26-47 \%)$ vs $41 \%$ (95\% CI, 31-50\%), $P=0.59$, respectively]. Skin microvascular function is preserved in early, DMARD-naive RA patients with moderately active RA but low systemic inflammatory activity. Both the extent of the systemic inflammation and disease duration, therefore, may be important determinants of microvascular dysfunction and subsequent increased risk for cardiovascular disease.

Keywords Cardiovascular disease · Inflammation . Iontophoresis $\cdot$ Rheumatoid arthritis · Vascular function

\section{Introduction}

Cardiovascular disease (CVD) has been recognized as the major cause of excess morbidity and mortality in patients with rheumatoid arthritis (RA) [1-3]. This increased cardiovascular risk in RA may partly be due to traditional cardiovascular risk factors, i.e., an atherogenic lipid profile and hypertension [4], but chronic inflammation is also thought to be important [5-9].

Inflammation-induced vascular dysfunction of the macrocirculation and microcirculation, in particular impaired endothelium-dependent vasodilatation, may predispose RA patients to CVD [4, 10, 11]. Macrovascular endothelial dysfunction precedes and initiates atherosclerosis and is a predictor of long-term cardiovascular risk [12]. Microvascular endothelial dysfunction, on the other 
hand, is important not only in the development of target organ damage in the heart and kidney, but also in the development of cardiovascular risk factors such as hypertension and insulin resistance [13-15]. Progressive impairment of microvascular endothelium-dependent vasodilatation of the skin is associated with an increasing coronary heart disease risk [16].

In longstanding RA, microvascular endotheliumdependent vasodilatation is impaired and associated with increased C-reactive protein (CRP) levels [17-19]. Moreover, anti-inflammatory therapy improves both peripheral (cutaneous) and myocardial microvascular dysfunction in RA patients $[20,21]$. This underlines the fact that the atherogenic process is not limited to plaque formation in large conduit vessels but is associated also with impaired microvascular function that plays an important role in regulating tissue perfusion, including myocardial perfusion and associated ischemia.

An intriguing question is at what point in the inflammatory disease course abnormalities in (micro)vascular function occur. Impaired microvascular endothelium-dependent vasodilatation can be demonstrated in patients with longstanding RA with low disease activity [20]. In addition, a flare of inflammatory activity in RA patients impairs microvascular endothelium-dependent vasodilatation even more, whereas inflammatory suppression does not restore vasoreactivity completely to normal [21]. In newly diagnosed RA patients and high systemic inflammation, both endothelium-dependent and endotheliumindependent vasodilatation of the resistance vessels are impaired as assessed with venous occlusion plethysmography [10].

It is presently unknown whether microvascular dysfunction is already present in early DMARD-naive RA patients with moderate disease but low systemic inflammatory activity. The aim of the study was to establish whether microvascular endothelium-dependent vasodilatation and capillary recruitment is impaired in patients with very early, DMARD-naive RA with low systemic inflammation compared to healthy controls.

\section{Patients and methods}

\section{Subjects}

\section{Early untreated $R A$}

Fifteen consecutive eligible patients (12 females) with RA were studied. Diagnosis was confirmed using the 1987 ACR criteria, [22] and low systemic inflammatory activity was defined as a CRP level $\leq 20 \mathrm{mg} / \mathrm{l}$. The vascular function study was performed $<2$ weeks after the diagnosis of RA and prior to treatment with diseasemodifying anti-rheumatic drugs (DMARDs) or oral corticosteroids. A total of 15 age- and sex-matched healthy subjects were studied as a control group. Clinical and biochemical characteristics of the study groups are shown in Table 1. Exclusion criteria were diabetes mellitus, hypertension, history of cardiovascular disease, Raynaud's syndrome, scleroderma, concurrent infection, thyroid dysfunction, and current or recent medication which might affect vascular function, except nonsteroidal anti-inflammatory drugs.

All participants gave written informed consent and the study protocol was approved by the Medical Ethics Committee of the Slotervaart Hospital, Jan van Breemen Institute and BovenIJ Hospital.

Study design

Microvascular measurements were conducted in a quiet, temperature-controlled room $\left(T=23.4 \pm 0.4^{\circ} \mathrm{C}\right)$ after 20 30 min of acclimatization, with the subjects in the sitting position and the investigated non-dominant hand at heart level. Nailfold capillary studies and iontophoresis studies were performed on the same day by a single experienced investigator (IvE). Subjects were asked to refrain from beverages other than water (especially no caffeine or alcohol), smoking, medication except acetaminophen if necessary, and meals from midnight at the testing day. Nailfold capillaries in the dorsal skin of the third finger were visualized by a capillary microscope as previously described [23, 24]. Nailfold capillaries were recorded on videotape before and after 4 min of arterial occlusion with a digital cuff. This procedure was performed twice, and the mean of both measurements was used for analyses. In addition, venous congestion, with the digital cuff inflated to $60 \mathrm{mmHg}$ for $60 \mathrm{~s}$, was applied to expose a maximal number of non-perfused capillaries. Capillaries were counted by a single observer using the naked eye from a freeze-framed reproduction of the videotape and from the running videotape, when it was uncertain whether a capillary was present or not. Baseline capillary density was defined as the number of continuously erythrocyteperfused capillaries during a 15 -s period. Intermittently perfused capillaries were also visible and are proposed to form an important functional reserve that can be recruited during post-occlusive hyperemia. The maximum number of capillaries visible directly after cuff release was counted for 30 s. Post-occlusive capillary recruitment was calculated by dividing the increase in density by the baseline density. The day to day coefficient of variation $(\mathrm{CV})$ of the capillary density in resting state was $2.3 \pm 1.8 \%$. The $\mathrm{CV}$ of the 
Table 1 Baseline characteristics of the RA patients and controls

Data are mean $+/-$ SD or median (interquartile range); pulse pressure $=$ systolic blood pressure - diastolic blood pressure

$A C P A$ anti-citrullinated protein/ peptide antibodies, ESR erythrocyte sedimentation rate, $C R P$

C-reactive protein, $H D L-c$ high-density lipoprotein cholesterol, $L D L-c$ low-density lipoprotein cholesterol, NSAID non-steroidal anti-inflammatory drug, $N / A$ not applicable

\begin{tabular}{lllc}
\hline Characteristics & $\begin{array}{l}\text { Patients with arthritis } \\
(n=15)\end{array}$ & $\begin{array}{l}\text { Healthy controls } \\
(n=15)\end{array}$ & $P$ value \\
\hline Age, years & $48 \pm 10$ & $48 \pm 10$ & 0.92 \\
Female, $n$ (\%) & $12(80)$ & $12(80)$ & N/A \\
Symptom duration, months & $5(4-12)$ & N/A & N/A \\
Rheumatoid factor (RF) positive, $n$ (\%) & $11(73)$ & N/A & N/A \\
ACPA positive, $n$ (\%) & $13(87)$ & N/A & N/A \\
Erosive, $n$ (\%) & $3(20)$ & N/A & N/A \\
Disease activity score (DAS28) & $4.7(0.95)$ & N/A & N/A \\
ESR, mm/h & $18(11-35)$ & $5(3-8)$ & $<0.001$ \\
CRP, mg/l & $3(2-17)$ & $1(1-2)$ & 0.002 \\
Fasting glucose & $4.8(4.2-5.3)$ & $4.5(4.2-4.7)$ & 0.38 \\
Total cholesterol & $4.7(4.0-5.3)$ & $5.4(4.1-5.7)$ & 0.42 \\
HDL-c & $1.52(1.31-1.87)$ & $1.42(1.27-1.88)$ & 0.78 \\
LDL-c & $2.70(2.11-3.37)$ & $2.72(2.01-3.88)$ & 0.68 \\
Triglycerides & $1.01(0.78-1.78)$ & $0.99(0.58-1.31)$ & 0.26 \\
Systolic blood pressure, mmHg & $126 \pm 15$ & $118 \pm 7$ & 0.1 \\
Diastolic blood pressure, mmHg & $80 \pm 8$ & $79 \pm 6$ & 1.0 \\
Smoking $(\%)$ & $2(13)$ & $1(7)$ & 0.5 \\
NSAID use, $n$ (\%) & $10(67)$ & N/A & N/A \\
Body mass index (BMI) & $24.5(22.4-27.4)$ & $24.4(22.1-25.2)$ & 0.42 \\
\hline
\end{tabular}

percentage capillary recruitment and absolute capillary recruitment during post-occlusive hyperemia were $8.3 \pm$ $4.9 \%$ and $6.2 \pm 4.3 \%$, respectively.

Endothelium-(in)dependent vasodilatation of forearm skin microcirculation was evaluated by iontophoresis of acetylcholine and sodium nitroprusside in combination with laser Doppler fluxmetry as previously described in more detail [23, 25]. Acetylcholine (1\%, Miochol-E, Théa Pharma, Zoetermeer, the Netherlands) was delivered with an anodal current; seven doses $(0.1 \mathrm{~mA}$ for $20 \mathrm{~s})$ were delivered, with a 60-s interval between each dose. Sodium nitroprusside $(0.01 \%$, Haagse ziekenhuis apotheek) was delivered with a cathodal current; nine doses $(0.2 \mathrm{~mA}$ for 20 s) were delivered, with a 90-s interval between each dose. Acetylcholine-dependent laser Doppler flux was measured on the non-dominant forearm, whereas nitroprusside-dependent laser Doppler flux was measured at the same spot on the opposite forearm, with approximately 15 min elapsed between the two measurements. The day to day $\mathrm{CV}$ of the percentage increase from baseline to the final $2 \mathrm{~min}$ of the plateau phase was $9.8 \pm 5.6 \%$ for acetylcholine and $8.3 \pm 5.4 \%$ for sodium nitroprusside.

\section{Assessment of inflammatory parameters}

Disease activity was measured by calculating the disease activity score of 28 joints (DAS28) [26]. CRP levels were determined using the Roche/Hitachi cobas 6000 analyzer, based on the principle of particle-enhanced immunological agglutination (Roche Diagnostics GmbH, D-68298, Mannheim, Germany). Values are expressed in milligrams/litre. A CRP below $10 \mathrm{mg} / \mathrm{L}$ was considered to be normal. ESR was determined with local measurement techniques (Westergren method) and expressed in millimeter per hour.

\section{Statistical analyses}

Data are expressed as mean (SD) or median (range) as appropriate. The distribution of variables was tested for normality and transformed if necessary. Student's $t$ test was used to compare continuous normally distributed variables within patients and matched controls. We used nonparametric Mann-Whitney $U$ tests when appropriate. For dichotomous variables, Pearson chi-square test was used. Correlations between variables were analysed by using Pearson correlation or Spearman's rho tests when appropriate. A two-tailed probability value of $P<0.05$ was considered (statistically) significant.

Power calculations based on repeat microvascular endothelium-dependent responses measured at two-time points 3 months apart in 23 individuals [27], suggest that it is possible to detect a difference of $270 \%$ points with $85 \%$ power at $P<0.05$ change using a paired comparison in 15 patients. 
Table 2 Microvascular measurement

Peak capillary density was defined as the maximum number of capillaries visible directly after arterial occlusion during post-ischemic hyperaemia. Venous occlusion represents the maximal number of nonperfused capillaries exposed after venous congestion. Data are mean $+/-\mathrm{SD}$ or median (interquartile range). Variables were tested using Student's $t$ test or Mann-Whitney $U$ test

$R A$ rheumatoid arthritis, Ach aceltycholine, $S N P$ sodium nitroprusside

\begin{tabular}{llll}
\hline & RA patients & Healthy controls & $P$ value \\
\hline Ach-mediated vasodilatation & $n=15$ & $n=15$ & \\
Skin temperature, ${ }^{\circ} \mathrm{C}$ & $30.3 \pm 0.9$ & $29.9 \pm 0.7$ & 0.12 \\
Baseline skin perfusion, PU & $8.5(3.7-14.5)$ & $6.8(4.6-8.0)$ & 0.58 \\
Ach-mediated vasodilatation, \% & $709 \pm 454$ & $797 \pm 435$ & 0.59 \\
SNP-mediated vasodilatation & & & \\
Skin temperature, ${ }^{\circ} \mathrm{C}$ & $30.0 \pm 0.9$ & $29.8 \pm 0.8$ & 0.47 \\
Baseline skin perfusion, PU & $5.3(3.6-7.3)$ & $6.7(5.1-9.6)$ & 0.25 \\
SNP-mediated vasodilatation, $\%$ & $1,292 \pm 772$ & $1,094 \pm 638$ & 0.45 \\
Capillary recruitment & $n=14$ & $n=15$ & \\
Skin temperature, ${ }^{\circ} \mathrm{C}$ & $30.2 \pm 1.4$ & $29.7 \pm 1.3$ & 0.24 \\
Baseline capillary density, number $/ \mathrm{mm}^{2}$ & $49 \pm 11$ & $46 \pm 12$ & 0.57 \\
Peak capillary density, number $/ \mathrm{mm}^{2}$ & $66 \pm 15$ & $64 \pm 16$ & 0.80 \\
Venous occlusion, number $/ \mathrm{mm}^{2}$ & $72 \pm 16$ & $68 \pm 18$ & 0.56 \\
Absolute increase, number $/ \mathrm{mm}^{2}$ & $17 \pm 8$ & $18 \pm 8$ & 0.79 \\
Capillary recruitment, $\%$ & $37 \pm 18$ & $41 \pm 18$ & 0.56 \\
\hline
\end{tabular}

\section{Results}

\section{Characteristics}

Baseline, demographic, and clinical characteristics of patients are shown in Table 1. The mean DAS28 score was 4.7 and CRP and ESR levels were significantly higher in patients compared to controls. The median symptom duration was 5 months.

Microvascular function is not disturbed in very early untreated arthritis

\section{Endothelial (in)dependent vasodilatation}

Microvascular vasodilatation in response to acetylcholine (endothelium dependent) in RA patients was comparable to controls [709\% (95\% CI, 457-961\%) vs 797\% (95\% CI,

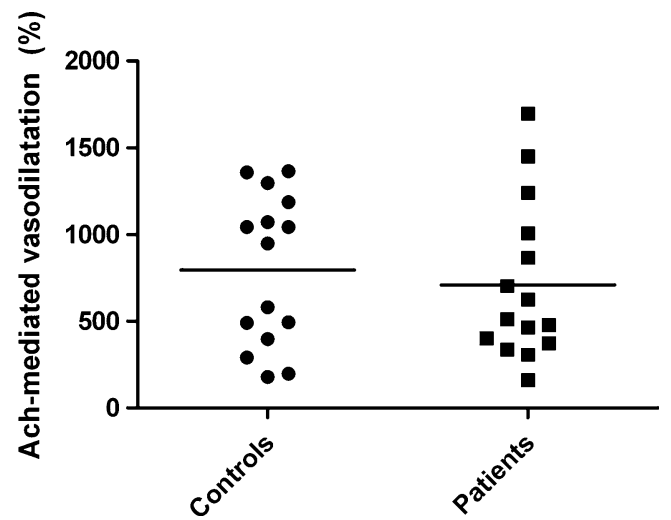

Fig. 1 Acetylcholine-mediated vasodilatation in controls and RA patients. The mean of vasodilatation, indicated by the horizontal line, is comparable in patients and controls. $A C h$ acetylcholine
556-1,037\%), $P=0.59$; Table 2 and Fig. 1]. The response to sodium nitroprusside (endothelium independent) also did not differ significantly between patients and controls [1,292\% (95\% CI, 865-1,720\%) vs 1,094\% (95\% CI, $741-1,448 \%), P=0.45]$.

\section{Capillary density and recruitment}

Baseline capillary density was similar in both groups, $49 / \mathrm{mm}^{2}$ in patients vs $46 / \mathrm{mm}^{2}$ in controls. The absolute and relative post- ischemic capillary recruitment did not differ between patients and controls (17 vs $18 \mathrm{~mm}^{2}$, respectively for absolute increase, $P=0.79$ and $37 \%(95 \%$ CI, 26-47\%) vs 41\% (95\% CI, 31-50\%), respectively for relative increase, $P=0.56)$. The total number of anatomically present capillaries visible after venous occlusion was 72 in patients vs 68 in controls, which was not different ( $P=0.56$; Table 2, Fig. 2).

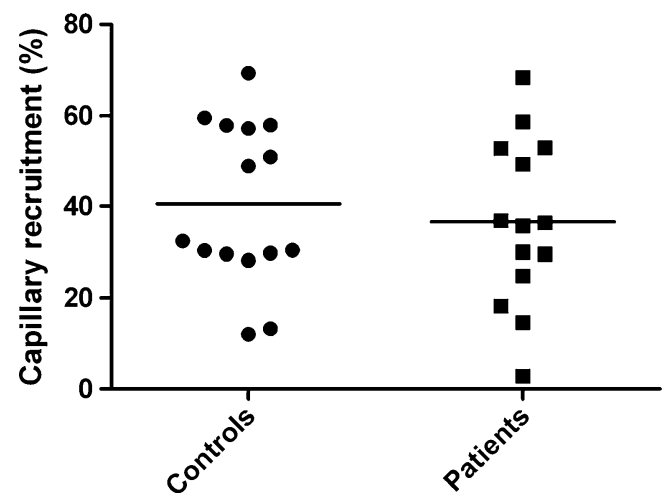

Fig. 2 Capillary recruitment depicted as the percentual increase of visible capillary numbers between baseline and after post-occlusive hyperaemia 
No correlations between microvascular function and disease activity markers and symptom duration

We did not find significant correlations between CRP or ESR or DAS28 and endothelium-dependent vasodilatation or capillary recruitment. The endothelium-dependent vasodilatation and capillary recruitment did not correlate significantly with symptom duration.

\section{Discussion}

In the present study, we observed a preserved microvascular endothelium-dependent vasodilatation and capillary recruitment during reactive hyperemia in DMARD-naive patients with newly diagnosed RA and low systemic inflammatory activity. Peripheral and coronary microvascular dysfunction is considered important in the development of cardiovascular disease [14, 28]. Previous studies demonstrated that coronary and peripheral microvascular dysfunction is apparent in longstanding established RA with high, but also low inflammatory activity $[11,18,19]$. Moreover, antiinflammatory therapy improves microvascular function, but does not completely restore it $[18,24]$. This persisting microvascular dysfunction may be caused by cumulative effects of inflammation, which in the long run lead to irreversible vascular damage. The finding of an inverse association between coronary microvascular function and disease duration in RA is compatible with such an explanation [20]. On the other hand, microvascular dysfunction may already be present at the time of diagnosis because subtle increased levels sometimes within the normal range of C-reactive protein can already be detected years before the onset of clinical RA [29]. Our findings, however, do not support this, as we found preserved microvascular function in patients with newly diagnosed, moderately severe RA with low systemic inflammatory activity. Interestingly, the CRP levels in our newly diagnosed RA patients are comparable to the CRP levels $(4.2 \mathrm{mg} / \mathrm{L})$ of patients with longstanding RA demonstrating impaired coronary microvascular function [20], suggesting that disease duration is an independent determinant of microvascular function. Nevertheless, newly diagnosed patients with RA do exhibit impaired endotheliumdependent and endothelium-independent vasodilatation of small arteries and resistance vessels if systemic inflammatory activity is more pronounced (i.e., CRP $29 \pm 10 \mathrm{mg} / \mathrm{L}$ ) [10]. Moreover, suppression of inflammatory activity seems to restore vasodilatory function [10]. These findings, together with our finding, suggest that systemic inflammatory activity is necessary to cause microvascular dysfunction, which is reversible early in the disease course, but becomes irreversible after a longer disease duration.
Obviously, with relatively low patient numbers, a type 2 error may occur more easily. Although we cannot completely exclude a difference in endothelium-dependent vasodilatation between RA patients and control subjects, it should be realized that the observed difference was very small (88 percentage point difference). To put this difference in perspective, in patients with longstanding RA, hypertension, obesity, or individuals at increased coronary heart disease risk, the difference in endotheliumdependent vasodilatation, as compared with healthy controls, exceeds 300 percentage points $[16,18,25,30]$. In conclusion, the present study showed that skin microvascular function is not impaired in very early DMARD-naive RA patients with low systemic inflammation, compared to healthy controls.

\section{Disclosures None}

Open Access This article is distributed under the terms of the Creative Commons Attribution Noncommercial License which permits any noncommercial use, distribution, and reproduction in any medium, provided the original author(s) and source are credited.

\section{References}

1. del Rincon ID, Williams K, Stern MP, Freeman GL, Escalante (2001) High incidence of cardiovascular events in a rheumatoid arthritis cohort not explained by traditional cardiac risk factors. Arthritis Rheum 44:2737-2745

2. Goodson NJ, Wiles NJ, Lunt M, Barrett EM, Silman AJ, Symmons DP (2002) Mortality in early inflammatory polyarthritis: cardiovascular mortality is increased in seropositive patients. Arthritis Rheum 46:2010-2019

3. Solomon DH, Karlson EW, Rimm EB, Cannuscio CC, Mandl LA, Manson JE, Stampfer MJ, Curhan GC (2003) Cardiovascular morbidity and mortality in women diagnosed with rheumatoid arthritis. Circulation 107:1303-1307

4. Sattar N, McCarey DW, Capell H, McInnes IB (2003) Explaining how "high-grade" systemic inflammation accelerates vascular risk in rheumatoid arthritis. Circulation 108:29572963

5. Del Rincon I, Williams K, Stern MP, Freeman GL, O'Leary DH, Escalante A (2003) Association between carotid atherosclerosis and markers of inflammation in rheumatoid arthritis patients and healthy subjects. Arthritis Rheum 48:1833-1840

6. Gonzalez-Gay MA, Gonzalez-Juanatey C, Martin J (2005) Rheumatoid arthritis: a disease associated with accelerated atherogenesis. Semin Arthritis Rheum 35:8-17

7. Van Doornum S, McColl G, Wicks IP (2002) Accelerated atherosclerosis: an extraarticular feature of rheumatoid arthritis? Arthritis Rheum 46:862-873

8. Wallberg-Jonsson S, Johansson H, Ohman ML, RantapaaDahlqvist S (1999) Extent of inflammation predicts cardiovascular disease and overall mortality in seropositive rheumatoid arthritis. A retrospective cohort study from disease onset. J Rheumatol 26:2562-2571 
9. Del Rincon ID, O’Leary DH, Freeman GL, Escalante A (2007) Acceleration of atherosclerosis during the course of rheumatoid arthritis. Atherosclerosis 195:354-360

10. Bergholm R, Leirisalo-Repo M, Vehkavaara S, Makimattila S, Taskinen MR, Yki-Jarvinen H (2002) Impaired responsiveness to NO in newly diagnosed patients with rheumatoid arthritis. Arterioscler Thromb Vasc Biol 22:1637-1641

11. Hansel S, Lassig G, Pistrosch F, Passauer J (2003) Endothelial dysfunction in young patients with long-term rheumatoid arthritis and low disease activity. Atherosclerosis 170:177-180

12. Yeboah J, Crouse JR, Hsu FC, Burke GL, Herrington DM (2007) Brachial flow-mediated dilation predicts incident cardiovascular events in older adults: the Cardiovascular Health Study. Circulation 115:2390-2397

13. Cheung N, Bluemke DA, Klein R, Sharrett AR, Islam FM, Cotch MF, Klein BE, Criqui MH, Wong TY (2007) Retinal arteriolar narrowing and left ventricular remodeling: the multi-ethnic study of atherosclerosis. J Am Coll Cardiol 50:48-55

14. Serne EH, de Jongh RT, Eringa EC, IJzerman RG, Stehouwer CD (2007) Microvascular dysfunction: a potential pathophysiological role in the metabolic syndrome. Hypertension 50:204-211

15. Struijker-Boudier HA, Rosei AE, Bruneval P, Camici PG, Christ F, Henrion D, Lévy BI, Pries A, Vanoverschelde JL (2007) Evaluation of the microcirculation in hypertension and cardiovascular disease. Eur Heart J 28:2834-2840

16. IJzerman RG, de Jongh RT, Beijk MA, van Weissenbruch MM, Delemarre-van de Waal HA, Serne EH, Stehouwer CD (2003) Individuals at increased coronary heart disease risk are characterized by an impaired microvascular function in skin. Eur J Clin Invest 33:536-542

17. Galarraga B, Khan F, Kumar P, Pullar T, Belch JJ (2008) C-reactive protein: the underlying cause of microvascular dysfunction in rheumatoid arthritis. Rheumatology (Oxford) 47:1780-1784

18. Datta D, Ferrell WR, Sturrock RD, Jadhav ST, Sattar N (2007) Inflammatory suppression rapidly attenuates microvascular dysfunction in rheumatoid arthritis. Atherosclerosis 192:391-395

19. Arosio E, De Marchi S, Rigoni A, Prior M, Delva P, Lechi A (2007) Forearm haemodynamics, arterial stiffness and microcirculatory reactivity in rheumatoid arthritis. J Hypertens 25:12731278

20. Ciftci O, Yilmaz S, Topcu S, Caliskan M, Gullu H, Erdogan D, Pamuk BO, Yildirir A, Muderrisoglu H (2007) Impaired coronary microvascular function and increased intima-media thickness in rheumatoid arthritis. Atherosclerosis 198:332-337
21. Raza K, Banks M, Kitas GD (2005) Reversing myocardial microvascular disease in a patient with rheumatoid arthritis. J Rheumatol 32:754-756

22. Arnett FC, Edworthy SM, Bloch DA, McShane DJ, Fries JF, Cooper NS, Healey LA, Kaplan SR, Liang MH, Luthra HS et al (1988) The American Rheumatism Association 1987 revised criteria for the classification of rheumatoid arthritis. Arthritis Rheum 31:315-324

23. Serne EH, Stehouwer CD, ter Maaten JC, ter Wee PM, Rauwerda JA, Donker AJ, Gans RO (1999) Microvascular function relates to insulin sensitivity and blood pressure in normal subjects. Circulation 99:896-902

24. van Eijk IC, Peters MJ, Serne EH, van der Horst-Bruinsma IE, Dijkmans BA, Smulders YM, Nurmohamed MT (2009) Microvascular function is impaired in ankylosing spondylitis and improves after tumour necrosis alpha blockade. Ann Rheum Dis 68:362-366

25. Serne EH, Gans RO, ter Maaten JC, ter Wee PM, Donker AJ, Stehouwer CD (2001) Capillary recruitment is impaired in essential hypertension and relates to insulin's metabolic and vascular actions. Cardiovasc Res 49:161-168

26. Prevoo ML, van't Hof MA, Kuper HH, van Leeuwen MA, van de Putte LB, van Riel PL (1995) Modified disease activity scores that include twenty-eight-joint counts. Development and validation in a prospective longitudinal study of patients with rheumatoid arthritis. Arthritis Rheum 38(1):44-48

27. Schram MT, Stam F, de Jongh RT, de Vries G, van Dijk RA, Serné EH, Lampe D, Nanayakkara PW, Tushuizen ME, Scheffer PG, Schalkwijk CG, Kamper AM, Stehouwer CD (2003) The effect of calcium dobesilate on vascular endothelial function, blood pressure, and markers of oxidation in obese male smokers: a placebo-controlled randomised clinical trial. Atherosclerosis 170:59-72

28. Nielen MM, van Schaardenburg D, Reesink HW, Twisk JW, van de Stadt RJ, van der Horst-Bruinsma IE, de Gast T, Habibuw MR, Vandenbroucke JP, Dijkmans BA (2004) Increased levels of Creactive protein in serum from blood donors before the onset of rheumatoid arthritis. Arthritis Rheum 50:2423-2427

29. de Jongh RT, Serne EH, IJzerman RG, de Vries G, Stehouwer CD (2004) Impaired microvascular function in obesity: implications for obesity-associated microangiopathy, hypertension, and insulin resistance. Circulation 109:2529-2535

30. Camici PG, Crea F (2007) Coronary microvascular dysfunction. $\mathrm{N}$ Engl J Med 356:830-840 